\title{
ELECTRON TRANSFER IN PROTEINS
}

\author{
Harry B. Gray and Jay R. Winkler \\ Beckman Institute, California Institute of Technology, Pasadena, California 91125
}

KEY WORDS: electron tunneling, electronic coupling, reorganization energy, cytochrome $c$, myoglobin, azurin, photosynthetic reaction center, cytochrome $c$ oxidase

\begin{abstract}
Electron-transfer (ET) reactions are key steps in a diverse array of biological transformations ranging from photosynthesis to aerobic respiration. A powerful theoretical formalism has been developed that describes ET rates in terms of two parameters: the nuclear reorganization energy $(\lambda)$ and the electronic-coupling strength $\left(H_{\mathrm{AB}}\right)$. Studies of ET reactions in ruthenium-modified proteins have probed $\lambda$ and $H_{\mathrm{AB}}$ in several metalloproteins (cytochrome $c$, myoglobin, azurin). This work has shown that protein reorganization energies are sensitive to the medium surrounding the redox sites and that an aqueous environment, in particular, leads to large reorganization energies. Analyses of electronic-coupling strengths suggest that the efficiency of long-range ET depends on the protein secondary structure: $\beta$ sheets appear to mediate coupling more efficiently than $\alpha$-helical structures, and hydrogen bonds play a critical role in both.
\end{abstract}

\section{CONTENTS}

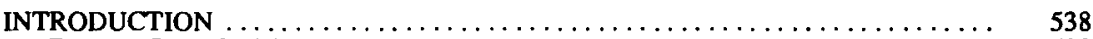

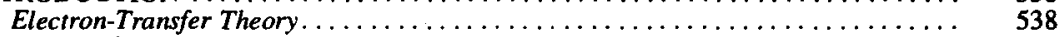

Ru-Modified Proteins ................................. 540

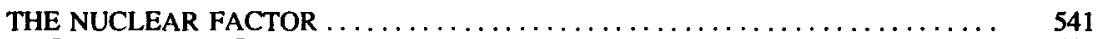

Reorganization Energy................................ 541

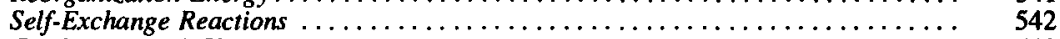

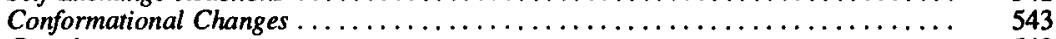

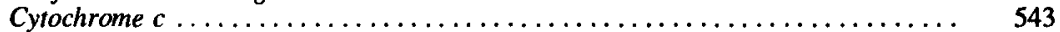

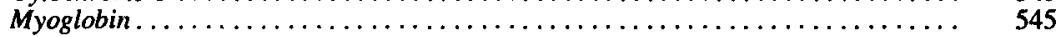

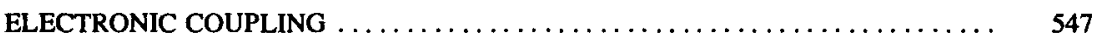

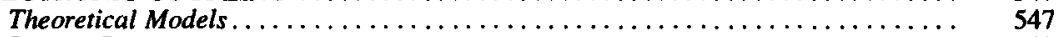

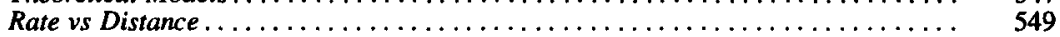

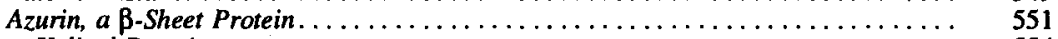

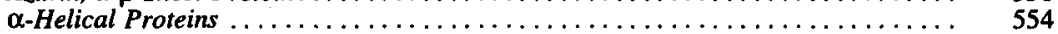

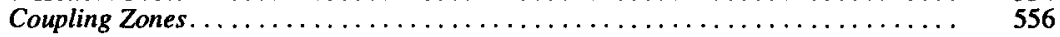




\section{INTRODUCTION}

A combination of $\mathrm{X}$-ray crystallographic experiments and biophysical investigations has produced a strikingly detailed picture of the initial events in photosynthesis $(1,2)$. The primary photochemical charge separation occurs with a time constant of $2 \mathrm{ps}$, creating a hole in the special pair $\left(\mathrm{BCh}_{2}\right)$ and placing an electron on the bacteriopheophytin (BPh) acceptor. Next there is a charge shift from the bacteriopheophytin to a menaquinone $\left(\mathrm{BPh}^{-} \rightarrow \mathrm{Q}_{\mathrm{A}}, \tau \sim\right.$ $100 \mathrm{ps}$ ), followed by hole-filling at the oxidized special pair by a reduced cytochrome ( $\mathrm{Fe}^{2+}$-cyt $\left.c \rightarrow \mathrm{BCh}_{2}^{+}, \tau \sim 10 \mathrm{~ns}\right)$.

The final charge shift from the menaquinone radical to ubiquinone occurs in $100 \mathrm{~ns}$. The overall result is charge separation across a membrane that stores roughly $0.3 \mathrm{eV}$ of chemical potential. The efficiency of this charge-separation process is very high; most of the energy-wasting recombination reactions are several orders of magnitude slower than the competing charge-shift reactions. Understanding the relative rates of these processes, as well as the curious fact that only one arm of the nearly twofold symmetric reaction center is electrontransfer (ET) active $(3,4)$, represents a major challenge for both theoreticians and experimentalists.

Some of the most critical steps in the functioning of mitochondrial enzymes are long-range ET reactions. Cytochrome $c$ oxidase, the terminal ET complex in aerobic respiration, catalyzes the four-electron reduction of $\mathrm{O}_{2}$ to $\mathrm{H}_{2} \mathrm{O}$ and pumps four protons across the inner mitochondrial membrane, creating a transmembrane potential that ultimately drives ATP synthesis (5-7). Cytochrome $c$ oxidase contains four distinct redox centers: cytochrome $a$ and binuclear $\mathrm{Cu}_{\mathrm{A}}$ are the primary electron acceptors; oxygen activation occurs at a binuclear cytochrome $a_{3} / \mathrm{Cu}_{\mathrm{B}}$ active site (8-10). Experimental studies of this enzyme have provided rate constants for many of its long-range ET reactions $(8,11)$, and recent time-resolved resonance Raman measurements have detailed the individual steps in the oxygen-activation reaction (12-15). In contrast to the primary events in photosynthesis, protein conformational dynamics as well as bond-breaking and bond-forming processes are intimately linked to the ET reactions of cytochrome $c$ oxidase.

\section{Electron-Transfer Theory}

The photosynthetic reaction center and cytochrome $c$ oxidase are just two of the many biological systems in which ET reactions play central roles. The unique simplicity of ET reactions has fostered the development of a powerful theoretical formalism that describes the rates of these processes in terms of a small number of parameters. The conceptual breakthrough that led to the development of ET theory was the recognition of the pivotal role played by 


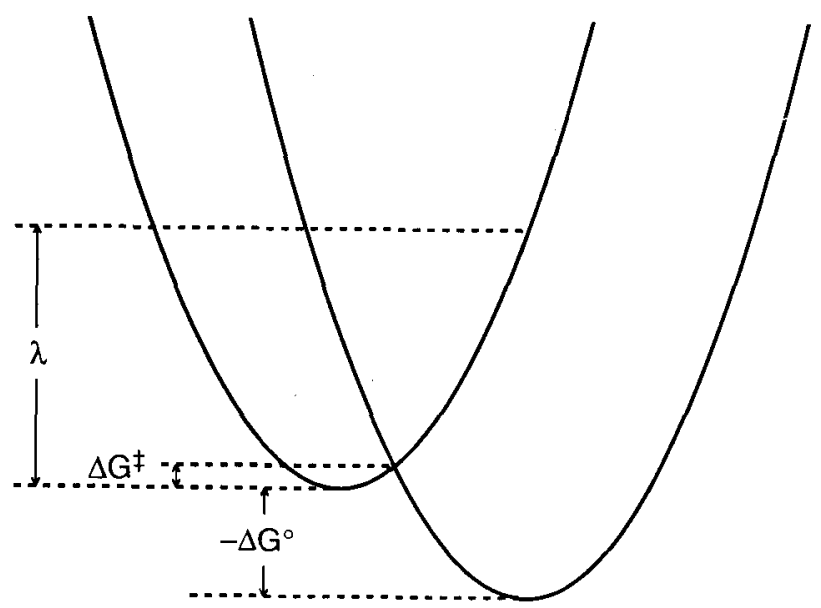

Figure $I$ Schematic representation of reactant and product potential-energy surfaces in electrontransfer reactions indicating the driving force $\left(-\Delta G^{\circ}\right)$, the activation free energy $\left(\Delta G^{\ddagger}\right)$, and the reorganization energy $(\lambda)$.

the Franck-Condon principle (16). Owing to the much higher electron velocities, nuclei will remain fixed during the actual transition from reactants to products. The transition state for this reaction must lie at a point in nuclearconfiguration space where the reactant and product states are degenerate (Figure 1). Hence, through fluctuations of the reacting molecules and their surroundings, the transition-state configuration will be reached and an electron can transfer.

Electron tunneling in proteins occurs in reactions where the electronic interaction between redox sites is relatively weak. Under these circumstances, the transition state for the electron-transfer reaction must be formed many times before reactants are successfully converted to products; the process is electronically nonadiabatic. Semiclassical theory (equation 1) (17) predicts that

$$
k_{\mathrm{ET}}=\left(4 \pi^{3} / h^{2} \lambda k_{\mathrm{B}} T\right) H_{\mathrm{AB}}^{2} \exp \left[-\left(\Delta \mathrm{G}^{\circ}+\lambda\right)^{2} / 4 \lambda k_{\mathrm{B}} T\right],
$$

the reaction rate for ET from a donor (D) to an acceptor (A) at fixed separation and orientation depends on the reaction driving force $\left(-G^{\circ}\right)$, a nuclear reorganization parameter $(\lambda)$, and the electronic-coupling strength between reactants and products at the transition state $\left(H_{\mathrm{AB}}\right)(17)$. This theory reduces a complex dynamical problem in multidimensional nuclear-configuration space 
to a simple expression comprised of just two parameters $\left(\lambda, H_{\mathrm{AB}}\right)$. Equation 1 naturally partitions into nuclear (exponential) and electronic (pre-exponential) terms: ET rates reach their maximum values $\left(k_{\mathrm{ET}}^{\circ}\right)$ when the nuclear factor is optimized $\left(-\Delta \mathrm{G}^{\circ}=\lambda\right)$; these $k_{\mathrm{ET}}^{\circ}$ values are limited only by the electronic-coupling strength $\left(H_{\mathrm{AB}}^{2}\right)$.

\section{Ru-Modified Proteins}

Investigations of the driving-force, temperature, and distance dependences of ET rates can be used to define the fundamental ET parameters $\lambda$ and $H_{\mathrm{AB}}$. Natural systems often are not amenable to the systematic studies that are required to explore the fundamental aspects of biological ET reactions. A successful alternative approach involves measurements of ET in metalloproteins that have been surface-labeled with redox-active molecules $(18,19)$. By varying the binding site and chemical composition of the probe molecule, it has been possible to elucidate the factors that control the rates of long-range ET reactions in proteins.

Ruthenium complexes are excellent reagents for protein modification and electron-transfer studies. $\mathrm{Ru}^{2+}$-aquo complexes readily react with surface His residues on proteins to form stable derivatives $(20,21)$. Low-spin pseudo-octahedral $\mathrm{Ru}$ complexes exhibit small structural changes upon redox cycling between the $\mathrm{Ru}^{2+}$ and $\mathrm{Ru}^{3+}$ formal oxidation states. Hence, the inner-sphere barriers to electron transfer $\left(\lambda_{\mathfrak{I}}\right)$ are small. With the appropriate choice of ligand, the $\mathrm{Ru}^{3+12+}$ reduction potential can be varied from $<0.0$ to $>1.5 \mathrm{~V}$ vs NHE. ET in a Ru-modified protein was first measured in $\mathrm{Ru}\left(\mathrm{NH}_{3}\right)_{5}(\mathrm{His} 33)^{3+}$ ferricytochrome $c(18)$. Photochemical methods were used to inject an electron into the $\mathrm{Ru}^{3+}$ site on the protein surface, and this kinetic product $\left(\mathrm{Ru}^{2+}-\mathrm{Fe}^{3+}\right)$ subsequently converted to the thermodynamic product $\left(\mathrm{Ru}^{3+}-\mathrm{Fe}^{2+}\right)$ by intramolecular electron transfer $\left(k_{\mathrm{ET}}=30 \mathrm{~s}^{-1}, \mathrm{~T}=295^{\circ} \mathrm{C},-\Delta \mathrm{G}^{\circ}=0.20 \mathrm{eV}\right)$. The early experimental measurements of long-range $\mathrm{ET}$ rates in $\mathrm{Ru}$-ammine-modified Fe-cyt $c(18,22,23)$ were followed by related studies of other Ru-ammine proteins [Zn-cyt c (24-26), myoglobin ( $\mathrm{Mb})$ (27-31), high-potential iron-sulfur protein (HiPIP) $(32,33)$, azurin $(34)$, plastocyanin $(35,36)$, stellacyanin $(37$, 38 ), cyt $b_{5}(39)$, and cyt $\left.c_{551}(40)\right]$.

Recent work on Ru-modified proteins has involved a Ru(bpy) $)_{2}(\mathrm{im})(\mathrm{HisX})^{2+}$ (bpy $=2,2^{\prime}$-bipyridine; $\mathrm{im}=$ imidazole) label $(41-45)$. In addition to the attractive ET properties of Ru-ammine systems, Ru-bpy complexes have an additional characteristic not found with the ammines: long-lived, luminescent metal-to-ligand charge-transfer excited states. These excited states enable a wider range of electron-transfer measurements than is possible with nonluminescent complexes (41). Furthermore, the bpy ligands raise the $\mathrm{Ru}^{3+12+}$ reduction potential to $>1 \mathrm{~V}$ vs NHE, making observed ET rates closer to $k_{\mathrm{ET}}^{\circ}$, which 
leads to more reliable estimates of $H_{\mathrm{AB}}$ and $\lambda$. Systematic investigations of Ru bpy-modified proteins have provided a detailed picture of long-range protein electron transfer.

\section{THE NUCLEAR FACTOR}

\section{Reorganization Energy}

The nuclear factor in equation 1 results from a classical treatment of nuclear motions in which all reorganization is described by a single harmonic coordinate. The parameter $\lambda$ is defined as the energy of the reactants at the equilibrium nuclear configuration of the products (Figure 1). The remarkable aspect of the nuclear factor is the predicted free-energy dependence (Figure 2). At low driving forces, rates increase with $-\Delta G^{\circ}$, but as the driving force moves into the region where $-\Delta \mathrm{G}^{\circ}>\lambda$, ET rates are predicted to decrease (inverted effect). Experimental studies of electron-transfer rates in synthetic model complexes $(46-50)$ and in biological systems $(11,51-53)$ have provided convincing evidence for inverted driving-force effects.

For ET reactions in polar solvents, the dominant contribution to $\lambda$ arises from reorientation of solvent molecules in response to the change in charge distribution of the reactants $\left(\lambda_{s}\right)$. Dielectric continuum models are commonly used in calculations of solvent reorganization. The earliest models treated the reactants as conducting spheres (17); later refinements dealt with charge shifts inside low dielectric cavities of regular (spherical, ellipsoidal) shape $(54,55)$. Embedding reactants in a low dielectric medium (e.g. a membrane) can dramatically reduce reorganization energies, but the effect on ET rates depends on the response of $\Delta \mathrm{G}^{\circ}$ to the nonpolar environment. Generally, low dielectric media will reduce the driving force for charge-separation reactions $(D+A \rightarrow$ $\left.D^{+}+A^{-}\right)$, but will have a smaller effect on the energetics of charge-shift reactions (e.g. $D^{-}+A \rightarrow D+A^{-}$).

The second component of the nuclear factor arises from changes in bond lengths and bond angles of the donor and acceptor following electron transfer. Classical descriptions of this inner-sphere reorganization $\left(\lambda_{1}\right)$ usually are not adequate, and quantum-mechanical refinements to equation 1 have been developed (56). The most significant consequences of quantized nuclear motions are found in the inverted region. Owing to nuclear tunneling through the activation barrier, highly exergonic reactions will not be as slow as predicted by the classical model. Distortions along coordinates associated with high-frequency vibrations $\left(>1000 \mathrm{~cm}^{-1}\right)$ can significantly attenuate the inverted effect (Figure 2).

The nuclear factor reflects the interplay between driving-force and reorganization energy that regulates ET rates. A reaction in the inverted region can be 


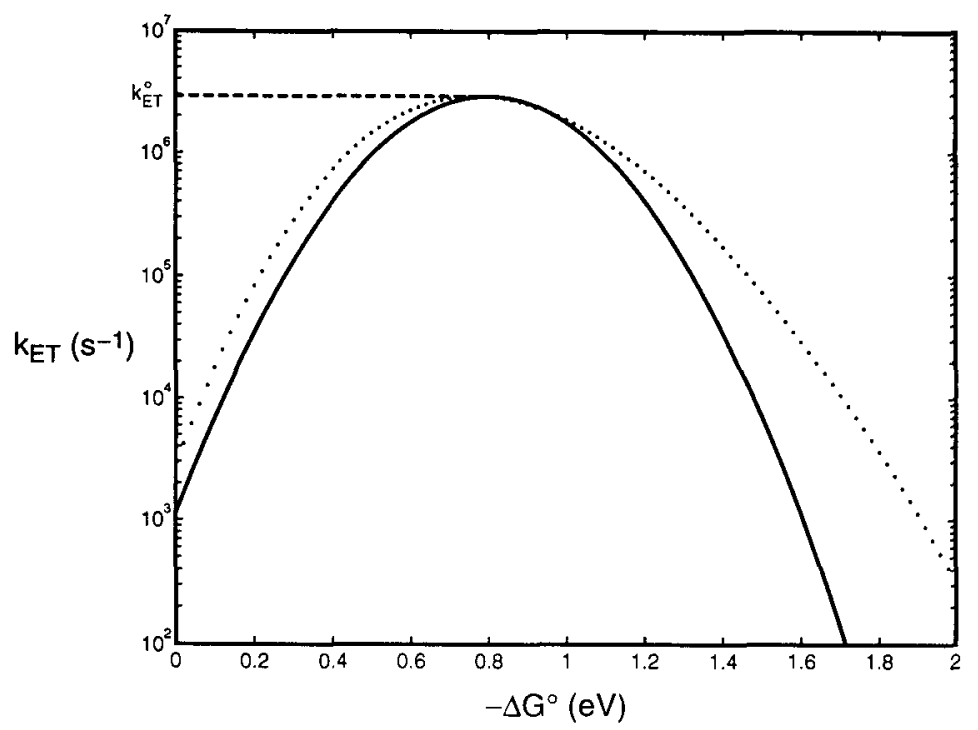

Figure 2 Predicted driving-force dependences of electron-transfer rates using classical (solid line) and quantum-mechanical (dotted line) descriptions of nuclear reorganization.

accelerated if a pathway is available that releases less free energy in the actual ET step. One such pathway leads to electronically excited products $\left({ }^{*} D^{+},{ }^{*} A^{-}\right)$; formation of these products lowers the ET driving force by an amount equal to the energy of the excited electronic state. An ET process that forms excited products will be the preferred pathway if its driving force is closer to $\lambda$ than that of a reaction forming ground-state products. Chemiluminescent ET reactions are a familiar example of such processes, and they are a clear demonstration of the inverted effect.

\section{Self-Exchange Reactions}

The simplest ET reactions are those in which the reactants are the same as the products. The driving force for these self-exchange reactions is zero, and the predicted activation free energy is just $\lambda / 4$ (equation 1). In his formulation of ET theory, Marcus developed expressions describing the rates and reorganization energies for ET reactions between different reagents (cross reactions) in terms of the self-exchange rates and reorganization energies for each reactant (17). These simple expressions permit cross-reaction rates to be estimated from self-exchange data, or self-exchange rates to be estimated from cross-reaction data, and have proven to be a powerful predictive tool in ET research. 


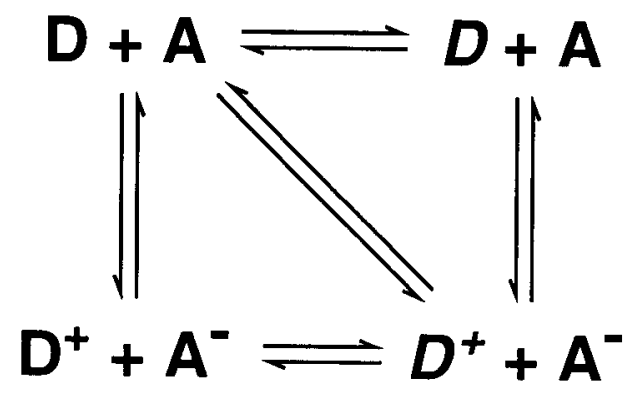

Figure 3 Redox reactions of a protein with two stable conformations in its reduced $(D, D)$ and oxidized $\left(\mathrm{D}^{+}, D^{+}\right)$states.

\section{Conformational Changes}

The multiple conformation, ionization, and ligand-binding states of biopolymers can severely complicate the electron-transfer problem. Oxidized and reduced proteins often have different conformations such that their redox reactions involve major nuclear rearrangements in addition to electron transfer. If a protein has multiple stable conformations, then new redox-reaction pathways become available. The redox reactions of a protein with two stable conformations in its reduced $(\mathrm{D}, D)$ and oxidized $\left(\mathrm{D}^{+}, D^{+}\right)$states can be represented by the scheme in Figure 3 (57-59).

A concerted conversion of $(\mathrm{D}+\mathrm{A})$ to $\left(D^{+}+\mathrm{A}^{-}\right)$is accompanied by a large reorganization barrier $(\lambda)$ due to the $\mathrm{D} \rightarrow D^{+}$conformation change. If the reorganization energy is great enough, sequential pathways could be more favorable. In a sequential mechanism, the conformational change could either precede $\left(\mathrm{D}+\mathrm{A} \rightarrow \mathrm{D}+\mathrm{A} \rightarrow D^{+}+\mathrm{A}^{-}\right)$or succeed $\left(\mathrm{D}+\mathrm{A} \rightarrow \mathrm{D}^{+}+\mathrm{A}^{-} \rightarrow D^{+}\right.$ $\left.+A^{-}\right)$the ET step. Many, if not most, biological redox reactions will involve complex reaction schemes in which elementary ET steps are not the rate-limiting processes.

\section{Cytochrome c}

A study of the driving-force dependence of intramolecular ET in $\mathrm{Ru}\left(\mathrm{NH}_{3}\right)_{4} \mathrm{~L}$ (His33)-Zn-cyt $c\left(\mathrm{~L}=\mathrm{NH}_{3}\right.$, pyridine, isonicotinamide) found that rates could be described by the parameters $\lambda=1.15 \mathrm{eV}$ and $H_{\mathrm{AB}}=0.1 \mathrm{~cm}^{-1}$ (Figure 4) (25). Application of the Marcus cross relation, using a value of $1.2 \mathrm{eV}$ for the electron self-exchange reorganization energy of $\mathrm{Ru}\left(\mathrm{NH}_{3}\right)_{4} \mathrm{~L}(\mathrm{His} 33)^{3+/ 2+}$, suggests that the self-exchange reorganization energy for $\mathrm{Zn}$-cyt $c$ is $1.2 \mathrm{eV}$. This value is in good agreement with the estimated self-exchange reorganization energy of native cyt $c(1.0 \mathrm{eV})(17)$. This analysis shows that the hydrophilic 


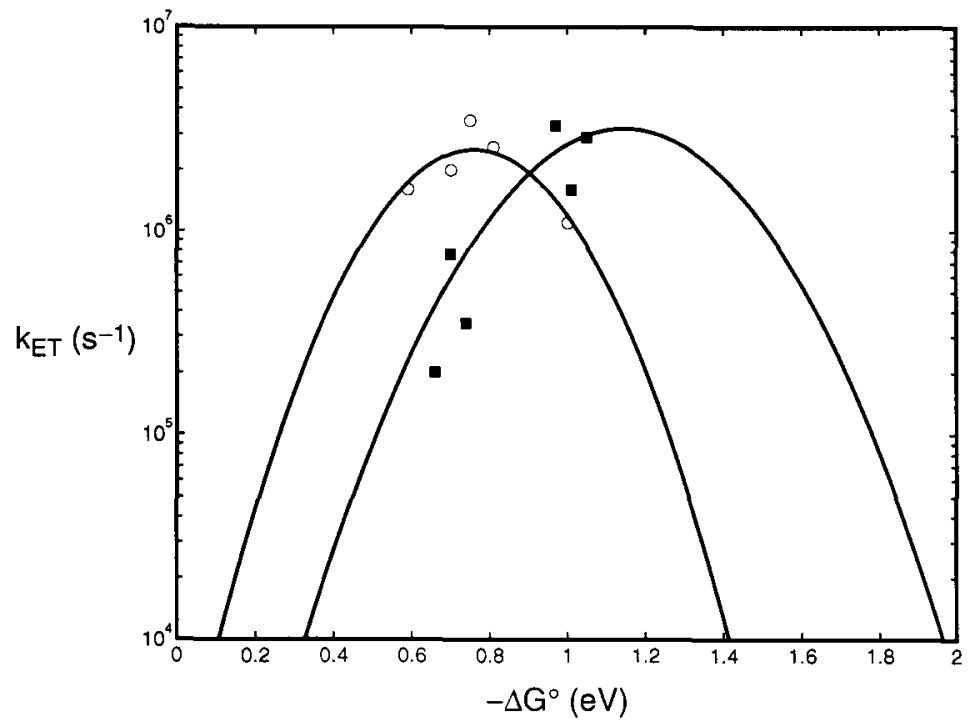

Figure 4 Driving-force dependence of electron-transfer rates in Ru-ammine-modified $\mathrm{Zn}$ substituted cytochrome $c$ (filled squares), and Ru-bpy-modified Fe-cytochrome $c$ (open circles).

Ru-ammine complex is responsible for half of the total reorganization energy in $\mathrm{Ru}$-ammine-modified cyt $c$ ET reactions.

Studies of self-exchange reactions have demonstrated that replacing ammonia ligands with diimine ligands substantially reduces the reorganization energy associated with $\mathrm{Ru}^{3+/ 2+} \mathrm{ET}(60)$. The difference can be attributed to a decrease in solvent polarization by the larger Ru-diimine ions and to somewhat smaller inner-sphere barriers as well. The reorganization energy for ET in $\mathrm{Ru}(\mathrm{bpy})_{2}$ (im)(His33)-Fe-cyt $c$ (bpy $=2,2$ '-bipyridine) was then expected to be less than $1.2 \mathrm{eV}$; a cross-relation calculation suggested a value of $0.8 \mathrm{eV}$. A recent study of the driving-force dependence of $\mathrm{Fe}^{2+} \rightarrow \mathrm{Ru}^{3+}$ ET rates in $\mathrm{Ru}(\mathrm{LL})_{2}(\mathrm{im})(\mathrm{His} 33)-\mathrm{Fe}$-cyt $c\left(\mathrm{LL}=\right.$ bpy, 4,4'- $\left(\mathrm{CH}_{3}\right)_{2}$-bpy, $4,4^{\prime}, 5,5^{\prime}-\left(\mathrm{CH}_{3}\right)_{4^{-}}$ bpy, $4,4^{\prime}-\left(\mathrm{CONH}\left(\mathrm{C}_{2} \mathrm{H}_{5}\right)\right)_{2}$-bpy) is in excellent agreement with this estimate $(\lambda$ $=0.74 \mathrm{eV}$, Figure 4) (44).

The significant difference in reorganization energy between $\mathrm{Ru}$-ammine and Ru-bpy-modified cy tochromes (Figure 4) highlights the important role of water in protein electron transfer. The bulky bpy ligands shield the charged metal center from the polar aqueous solution, reducing the solvent reorganization energy. In the same manner, the medium surrounding a metalloprotein active site will affect the reorganization energy associated with its ET reactions. A hydrophilic active site will lead to larger reorganization energies than a hy- 
drophobic site. Consequently, the kinetics of protein ET reactions will be very sensitive to the active-site environment.

Some have suggested that the electron-transfer reactions of cyt $c$ may be gated by protein conformational changes $(61,62)$. These ideas stem from observations that ferricytochrome $c$ is not as tightly folded as ferrocytochrome $c$ (63-65). Indeed, equilibrium titrations demonstrate that ferricytochrome $c$ unfolds at lower concentrations of denaturants [e.g. urea, guanidine hydrochloride (GuHCl)] than ferrocytochrome $c$. Extrapolations to zero denaturant concentration indicate that the free energy of folding is $-8 \mathrm{kcal} \mathrm{mol}^{-1}$ greater for the reduced protein in aqueous solution (65). In addition, ${ }^{1} \mathrm{H}$ NMR spectra have been interpreted in terms of a more flexible structure for ferricytochrome $c$ (63). A recent measurement of the $\mathrm{Fe}^{2+} \rightarrow \mathrm{Ru}^{3+} \mathrm{ET}$ rate in $\mathrm{Ru}\left(\mathrm{NH}_{3}\right)_{5}$ (His33)$\mathrm{Fe}$-cyt $c$ demonstrates that, contrary to earlier suggestions, ET in cyt $c$ is fully reversible and the ratio of rate constants for the $\mathrm{Ru}^{2+} \rightarrow \mathrm{Fe}^{3+}$ and $\mathrm{Fe}^{2+} \rightarrow \mathrm{Ru}^{3+}$ ET processes equals the equilibrium constant determined from electrochemical measurements (66). This observation provides compelling evidence that, at least on the timescales of these kinetics, conformational dynamics and energetics do not limit cyt $c$ ET reactions.

Gated ET may be involved in the reactions of cytochrome $c$ in the presence of denaturants $(\mathrm{GuHCl})$. The reduction potential of folded cyt $c\left(\mathrm{E}^{\circ}=0.26 \mathrm{~V}\right.$ vs NHE) is $-0.4 \mathrm{eV}$ greater than that of unfolded cyt $c(65)$. At intermediate $\mathrm{GuHCl}$ concentrations (3-4 M), ferrocytochrome $c$ is folded and ferricytochrome $c$ is unfolded, creating a situation similar to that represented in Figure 3. Owing to the scale of the nuclear rearrangement, redox cycling between oxidized and reduced proteins is unlikely to occur in concert with folding (or unfolding). Instead, the two processes should occur in sequence with the potential of the redox partner determining the course of the reaction. Recent work has shown that strong electron donors inject an electron into unfolded ferricytochrome to form a transient unfolded ferrocytochrome, which then rearranges to the folded structure in less than $100 \mathrm{~ms}$ (65). ET triggering methods have the potential to bridge the ns to ms measurement time gap for protein folding (65).

\section{Myoglobin}

Myoglobin $(\mathrm{Mb})$ is an oxygen-binding heme protein that, like cyt $c$, can participate in electron-transfer reactions. Unlike cyt $c$, however, Mb undergoes a coordination change upon cycling between the $\mathrm{Fe}^{3+}$ and $\mathrm{Fe}^{2+}$ oxidation states. The heme in $\mathrm{Fe}^{3+}-\mathrm{Mb}$ is a high-spin, six-coordinate complex with His93 and $\mathrm{H}_{2} \mathrm{O}$ axial ligands; $\mathrm{Fe}^{2+}-\mathrm{Mb}$ has a high-spin, five-coordinate heme bound only to His93 (67). This situation is analogous to that represented in Figure 3. The ET reactions of $\mathrm{Mb}$ are necessarily coupled to the dynamics and energetics of 
$\mathrm{H}_{2} \mathrm{O}$ binding to both the ferro- and ferri-hemes. This type of coordination change is not uncommon in heme enzymes, and it can have profound consequences for ET kinetics.

A cyclic voltammetric study suggests that water binding $\left(k_{\mathrm{b}}\right)$ and dissociation $\left(k_{\mathrm{f}}\right)$ in $\mathrm{Fe}^{2+}-\mathrm{Mb}$ are quite slow $\left(k_{\mathrm{f}}=1.0(5), k_{\mathrm{b}}=0.5(2) \mathrm{s}^{-1}\right)(68)$. This study also led to the suggestion that five-coordinate, high-spin $\mathrm{Fe}^{2+}-\mathrm{Mb}$ is electrochemically inactive and that water binding is the rate-limiting process for oxidation to met- $\mathrm{Mb}\left[\mathrm{Fe}\left(\mathrm{OH}_{2}\right)^{3+}-\mathrm{Mb}\right]$. Whether the same is true for homogeneous oxidations of $\mathrm{Fe}^{2+}-\mathrm{Mb}$ depends very much upon the reaction driving force. Observed rates of $\mathrm{Fe}^{2+}$ oxidation in $\mathrm{Ru}\left(\mathrm{NH}_{3}\right)_{4} \mathrm{~L}$ (His48)-modified $\mathrm{Mb}$ [L, $k_{\mathrm{ET}} \mathrm{s}^{-1}\left(-\Delta \mathrm{G}^{\circ}, \mathrm{eV}\right): \mathrm{NH}_{3}, 0.04(0.02) ; \mathrm{py}, 2.5(0.28)$; isn, $3.0(0.35)(30)$ ] are within an order of magnitude of the proposed $\mathrm{H}_{2} \mathrm{O}$-dissociation rate, but since two of the rates are at least five times faster than $k_{\mathrm{b}}$, the ET reaction is apparently not gated by the ligand-binding process. The slowest reaction $(\mathrm{L}=$ $\mathrm{NH}_{3}$ ) could involve a ligand-binding pre-equilibrium step prior to electron transfer. In the two faster reactions $(\mathrm{L}=\mathrm{py}$, isn), water binding to the heme iron must occur during or after electron transfer. If this process is concerted, then $\lambda$ will be substantially greater than the $1.2 \mathrm{eV}$ value found for ET reactions in Ru-modified cyt $c$. In a sequential ET/ligand-binding mechanism, the driving force for the ET process will be lower by an amount equal to the free-energy change for water binding to $\mathrm{Fe}^{3+}-\mathrm{Mb}$. Although the dynamics of ligand binding do not appear to limit these Ru-modified Mb ET reactions, the energetics of water binding to both $\mathrm{Fe}^{2+}-\mathrm{Mb}$ and $\mathrm{Fe}^{3+}-\mathrm{Mb}$ play a critical role.

Much of the complexity of $\mathrm{Mb}$ redox reactions can be eliminated by replacing the heme with luminescent metalloporphyrins (e.g. $\mathrm{ZnP}, \mathrm{MgP}, \mathrm{CdP}, \mathrm{H}_{2} \mathrm{P}$, $\mathrm{PdP}, \mathrm{PtP} ; \mathrm{P}=$ porphyrin dianion). A previous analysis of ET reactions in $\mathrm{Ru}$ (ammine)(His48)-modified, metal-substituted Mb suggested a reorganization energy of $1.26 \mathrm{eV}$ (30). The ET rates of Ru(ammine)(His48)-modified Fe-Mb could be described by this reorganization energy, but with a slightly smaller value of $H_{\mathrm{AB}}$. These results are quite similar to those found for $\mathrm{Ru}(\mathrm{am}-$ mine)(His33)-cyt $c$, but they provide no information about the role of the coordination change in the ET reaction.

These investigations of ET in Ru-modified cyt $c$ and $\mathrm{Mb}$ provide some insight into the factors affecting energies in heme proteins. The presence of water around one or both redox sites has a significant impact: More water leads to larger values of $\lambda$. Excluding water by burying redox centers inside hydrophobic pockets or in membranes can lead to unusually small reorganization energies. The redox cofactors of the photosynthetic reaction center are embedded in a membrane-spanning helical protein matrix, and extremely small reorganization energies have been estimated for the initial ET step in photosynthesis $(69,70)$. This small value of $\lambda$ leads to a deeply inverted charge-recombination reaction and is likely to be responsible for the overall efficiency 
of photochemical energy storage. The recent $x$-ray crystal structures of cytochrome $c$ oxidase will provide important information for the analysis of electron transfer in this enzyme $(9,10)$. Long-range ET reactions in cytochrome $c$ oxidase proceed at remarkably fast rates. The rate constant for ET from cyt $c$ to $\mathrm{Cu}_{\mathrm{A}}$ is $10^{5} \mathrm{~s}^{-1}\left(-\Delta \mathrm{G}^{\circ}=0.02 \mathrm{eV}\right)(71)$ and that for $\mathrm{Cu}_{\mathrm{A}} \rightarrow$ cyt $a$ ET is 2 $\times 10^{4} \mathrm{~s}^{-1}\left(-\Delta \mathrm{G}^{\circ}=0.1 \mathrm{eV} ; 19 \AA\right.$ metal-metal distance) $(9,11,72)$. Strong coupling (vide infra) and low reorganization energies are required to explain the observed ET rates.

\section{ELECTRONIC COUPLING}

\section{Theoretical Models}

Nonadiabatic ET reactions are characterized by weak electronic interaction between the reactants and products at the transition-state nuclear configuration $\left(H_{\mathrm{AB}} \ll k_{\mathrm{B}} \mathrm{T}\right)$. This coupling is directly related to the strength of the electronic interaction between the donor and acceptor (73). When donors and acceptors are separated by long distances $(>10 \AA)$, the D/A interaction will be quite small.

HOMOGENEOUS-BARRIER MODELS In 1974 Hopfield described biological ET in terms of electron tunneling through a square potential barrier (74). In this model, $H_{\mathrm{AB}}$ (and, hence, $k_{\mathrm{ET}}$ ) drops off exponentially with increasing D-A separation. The height of the tunneling barrier relative to the energies of the D/A states determines the distance-decay constant $(\beta)$. A decay constant in the range of $3.5-5 \AA^{-1}$ has been estimated for donors and acceptors separated by a vacuum and, as a practical matter, ET is prohibitively slow at D-A separations $(R)$ greater than $8 \AA\left(k_{\mathrm{ET}}^{\circ}<10 \mathrm{~s}^{-1}\right)$. An intervening medium between redox sites reduces the height of the tunneling barrier, leading to a smaller distancedecay constant. Hopfield estimated $\beta \sim 1.4 \AA^{-1}$ for biological ET reactions on the basis of measurements of the temperature dependence of ET from a cytochrome to the oxidized special pair in the photosynthetic reaction center of Chromatium vinosum (74). An 8- $\AA$ edge-edge separation was estimated on the basis of this decay constant; later structural studies revealed that the actual distance was somewhat greater $(12.3 \AA)$.

SUPEREXCHANGE-COUPLING MODELS The square-barrier models assume that the distant couplings result from direct overlap of localized donor and acceptor wavefunctions. In long-range ET $(R>10 \AA)$, the direct interaction between donors and acceptors is negligible; electronic states of the intervening bridge mediate the coupling via superexchange. If oxidized states of the bridge mediate the coupling, the process is referred to as hole transfer; mediation by 


\section{GRAY \& WINKLER}

reduced bridge states is known as electron transfer. In 1961 McConnell developed a superexchange coupling model to describe charge-transfer interactions between donors and acceptors separated by spacers comprised of $m$ identical repeat units (equation 2) (75). The total coupling depends upon the interaction between adjacent hole

$$
H_{\mathrm{AB}}=\left(h_{\mathrm{D}} / \Delta\right)\left(h_{\mathrm{j}} / \Delta\right)^{\mathrm{m}} h_{\mathrm{A}}
$$

or electron states in the bridge $\left(h_{\mathrm{j}}\right)$, the energy difference between the degenerate $D / A$ states and the bridge states $(\Delta)$, and the interactions between the $D$ and $\mathrm{A}$ states and the bridge $\left(h_{\mathrm{D}}, h_{\mathrm{A}}\right)$.

The McConnell model assumes that only nearest-neighbor interactions mediate the coupling and consequently predicts that $H_{\mathrm{AB}}$ will vary exponentially with the number of repeat units in the bridge. Several studies of the distance dependence of ET in synthetic donor-acceptor complexes agree quite well with this prediction. Ab initio calculations of $H_{\mathrm{AB}}$ for bridges composed of saturated alkane spacers, however, suggest that the simple superexchange model is not quantitatively accurate (76-79). Nonnearest-neighbor interactions were found to dominate the couplings and, except in a few cases, nearest-neighbor interactions were relatively unimportant. A particularly significant finding in these studies is that nonnearest-neighbor interactions make the coupling along a saturated alkane bridge quite sensitive to its conformation.

The medium separating redox sites in proteins is comprised of a complex array of bonded and nonbonded contacts, and an $a b$ initio calculation of coupling strengths is a formidable challenge. The homologous-bridge superexchange model (equation 2) is not suitable, because of the diverse interactions in proteins. Beratan, Onuchic, and their coworkers developed a generalization of the McConnell superexchange coupling model that accommodates the structural complexity of a protein matrix (80-84). In this tunneling-pathway model, the medium between $\mathrm{D}$ and $\mathrm{A}$ is decomposed into smaller subunits linked by covalent bonds, hydrogen bonds, or through-space jumps. Each link is assigned a coupling decay $\left(\varepsilon_{C}, \varepsilon_{H}, \varepsilon_{S}\right)$, and a structure-dependent searching algorithm is used to identify the optimum coupling pathway between the two redox sites. The total coupling of a single pathway is given as a repeated product of the couplings for the individual links:

A tunneling pathway can be described in terms of an effective covalent tunneling path comprised of $\mathbf{n}$ (nonintegral) covalent bonds, with a total length equal to $\sigma_{1}$ (equation 4). The relationship between $\sigma_{1}$ and the direct $\mathrm{D}-\mathrm{A}$ distance $(R)$ reflects 


$$
\begin{aligned}
& H_{\mathrm{AB}} \propto\left(\varepsilon_{\mathrm{C}}\right)^{\mathrm{n}} \\
& \sigma_{1}=\mathrm{n} \times 1.4 \AA / \text { bond }
\end{aligned}
$$$$
4 a \text {. }
$$

the coupling efficiency of a pathway (45). The variation of ET rates with $R$ depends upon the coupling decay for a single covalent bond $\left(\varepsilon_{\mathrm{C}}\right)$, and the magnitude of $\varepsilon_{\mathrm{C}}$ depends critically upon the energy of the tunneling electron relative to the energies of the bridge hole and electron states (85). In considering ET data from different protein systems, care must be taken to compare reactions in which oxidants (for hole tunneling) have similar reduction potentials.

\section{Rate vs Distance}

The D-A distance decay of protein ET rate constants depends on the capacity of the polypeptide matrix to mediate distant electronic couplings. In a seminal paper in 1992, Dutton and coworkers showed (86) that Hopfield's protein distance-decay constant $\left(1.4 \AA^{-1}\right)(74)$ could be used to estimate long-range ET rates in the photosynthetic reaction center (RC). Although Dutton's rate/distance correlation gives a rough indication of $\mathrm{RC}$ coupling strengths $(86$, 87), extensive theoretical work clearly shows that the intervening polypeptide structure must be taken into account in attempts to understand distant D-A couplings in other proteins (80-84, 88-97).

The tunneling-pathway model has proven to be one of the most useful methods for estimating long-range electronic couplings (80-82). Employing this model, Beratan, Betts, and Onuchic predicted in 1991 that proteins comprised largely of $\beta$-sheet structures would be more effective at mediating long-range couplings than those built from $\alpha$ helices (84). This analysis can be taken a step further by comparing the coupling efficiencies of individual protein secondary structural elements ( $\beta$ sheets, $\alpha$ helices). The coupling efficiency can be determined from the variation of $\sigma_{1}$ as a function of $R$. A linear $\sigma_{\mathrm{l}} / R$ relationship implies that $k_{\mathrm{ET}}^{\circ}$ will be an exponential function of $R$; the distance-decay constant is determined by the slope of the $\sigma_{1} / R$ plot and the value of $\varepsilon_{C}$.

A $\beta$ sheet is comprised of extended polypeptide chains interconnected by hydrogen bonds; the individual strands of $\beta$ sheets define nearly linear coupling pathways along the peptide backbone spanning $3.4 \AA$ per residue. The tunneling length for a $\beta$ strand exhibits an excellent linear correlation with $\beta$-carbon separation $\left(R_{\beta}\right.$, Figure 4$)$; the best linear fit with zero intercept yields a slope of $1.37 \sigma_{1} / R_{\beta}$ (distance-decay constant $=1.0 \AA^{-1}$ ). Couplings across a $\beta$ sheet depend upon the ability of hydrogen bonds to mediate the D/A interaction. The standard parameterization of the tunneling-pathway model defines the coupling decay across a hydrogen bond in terms of the heteroatom separation:

$$
\varepsilon_{\mathrm{H}}=\varepsilon_{\mathrm{C}}^{2} \exp [-1.7(R-2.8)]
$$




\section{0}

\section{GRAY \& WINKLER}

If the two heteroatoms are separated by twice the 1.4- $\AA$ covalent-bond distance, then the hydrogen-bond decay is assigned a value equal to that of a covalent bond (82). Longer heteroatom separations lead to weaker predicted couplings, but this relationship has not yet been confirmed experimentally.

In the coiled $\alpha$-helix structure a linear distance of just $1.5 \AA$ is spanned per residue. In the absence of mediation by hydrogen bonds, $\sigma_{1}$ is a very steep function of $R_{\beta}$, implying that an $\alpha$ helix is a poor conductor of electronic coupling (2.7 $\sigma_{1} / R_{\beta}$, distance-decay constant $=1.97 \AA^{-1}$, Figure 5) (45). If the hydrogen-bond networks in $\alpha$ helices mediate coupling, then the BeratanOnuchic parameterization of hydrogen-bond couplings suggests a $\sigma_{1} / R_{\beta}$ ratio of 1.72 (distance-decay constant $=1.26 \AA^{-1}$, Figure 5). Treating hydrogen bonds as covalent bonds further reduces this ratio $\left(1.29 \sigma_{1} / R_{\beta}\right.$, distance-decay constant $=0.94 \AA^{-1}$, Figure 5). Hydrogen-bond interactions will determine whether $\alpha$ helices are vastly inferior to or slightly better than $\beta$ sheets in mediating long-range electronic couplings.

The coiled helical structure leads to poorer $\sigma_{1} / R_{\beta}$ correlations, especially for values of $R_{\beta}$ under $10 \AA$. In this distance region, the tunneling pathway model predicts little variation in coupling efficiencies for the different secondary structures (Figure 5). The coupling in helical structures could be highly anisotropic. Electron transfer along a helix may have a very different distance dependence from ET across helices. In the latter cases, the coupling efficiency will depend on the nature of the interactions between helices. $\beta$ sheets and $\alpha$ helices are described by quite different peptide bond angles $(\phi$, $\varphi)$. Ab initio calculations on saturated hydrocarbons have suggested that different conformations provide different couplings (76). Thus, different values of $\varepsilon_{C}$ might be necessary to describe couplings in $\beta$ sheets and $\alpha$ helices.

Analyses of ET rate/distance relationships require a consistent definition of the D-A distance. When comparing rates from systems with different donors and/or acceptors, identifying a proper distance measure can be difficult. All maximum ET rates should extrapolate to a common adiabatic rate as $R$ approaches van der Waals contact. So-called edge-to-edge distances are often employed but introduce many ambiguities, not the least of which is defining the set of atoms that constitute the edges of D and A. For planar aromatic molecules (e.g. chlorophylls, pheophytins, quinones), edge-edge separations are usually defined on the basis of the shortest distance between aromatic carbon atoms of $\mathrm{D}$ and $\mathrm{A}$. In transition-metal complexes (e.g. Fe-heme, Ruammine, Ru-bpy), however, atoms on the periphery are not always well coupled to the central metal, and empirical evidence suggests that metal-metal distances are more appropriate. This dichotomy is by no means rigorously supported by experimental data, but instead represents the best available compromise. In the following analyses, edge-edge distances will be used for ET 


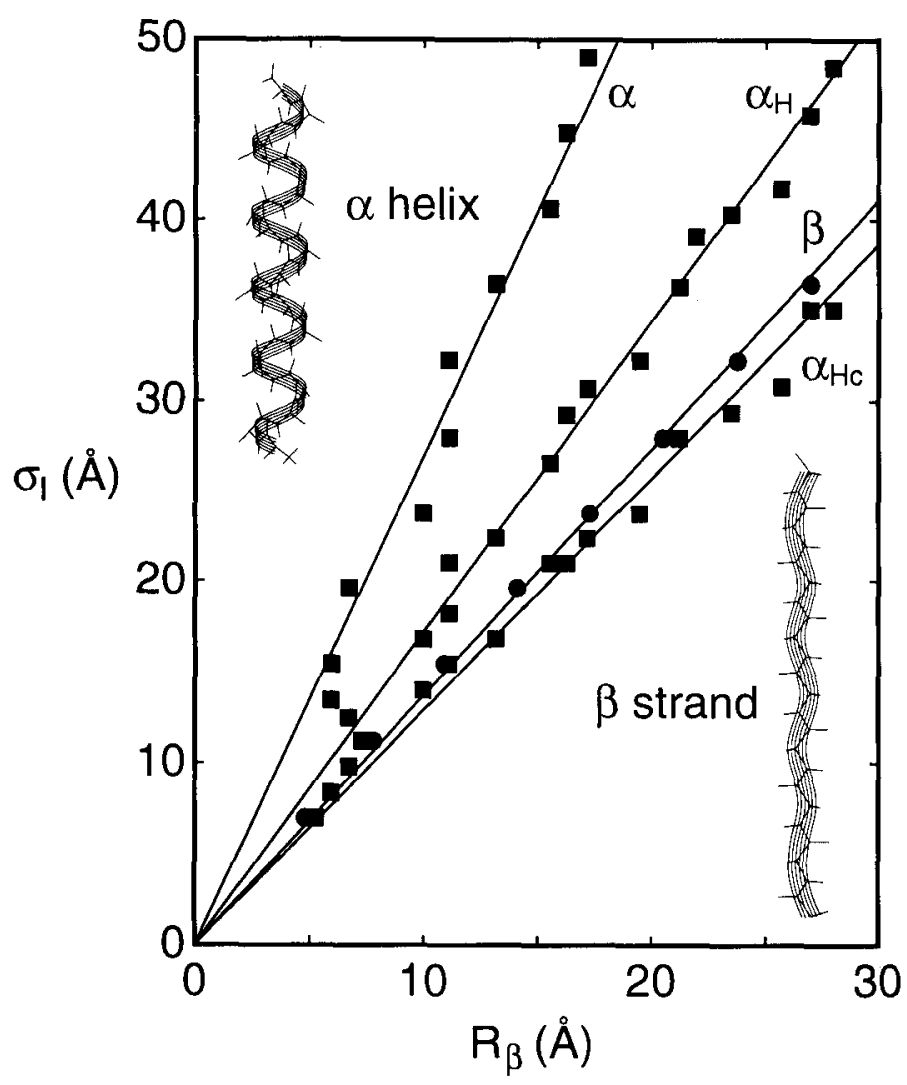

Figure 5 Plots of $\sigma_{1}$ vs $R_{\beta}$ for an idealized $\beta$ strand and $\alpha$ helix. The solid lines are the best linear fits with zero intercept. The slope of the $\beta$-strand line is 1.37 (circles). For the $\alpha$ helix (squares), three different treatments of the hydrogen-bond interaction were used: no mediation of coupling, $\alpha$ slope $=2.7$; Beratan-Onuchic parameterization of hydrogen-bond couplings, $\alpha_{\mathrm{H}}$ slope $=1.72$; hydrogen bonds treated as covalent bonds, $\alpha_{\text {Hc }}$ slope $=1.22$.

reactions between aromatic donors and acceptors, metal-metal separations will be used for reactions involving two transition-metal complexes, and edge-metal distances will be used for mixed metal/aromatic-molecule reactions.

\section{Azurin, a $\beta$-Sheet Protein}

A great deal of work has been done on blue copper proteins. In azurin, a prototypal blue protein with a $\beta$-barrel tertiary structure (Figure 6), the central $\mathrm{Cu}$ atom is coordinated to Cys112(S), His $117(\mathrm{~N})$, and His46 (N) donor atoms 


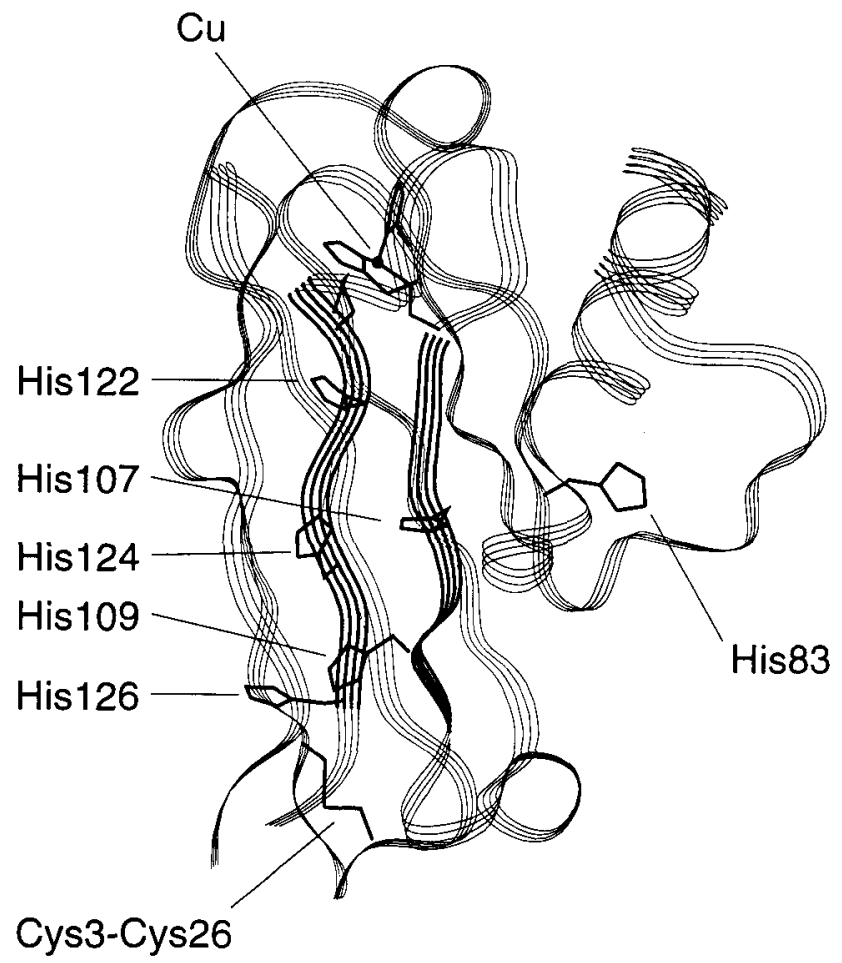

Figure 6 Structure of Pseudomonas aeruginosa azurin including the His residues that have been coordinated to $\mathrm{Ru}(\mathrm{bpy})_{2}(\mathrm{im})^{2+}$; the Cys3-Cys 26 disulfide group is also shown.

in a trigonal planar structure, with weakly interacting Met121 (S) and Gly45 (carbonyl $O$ atom) ligands above and below the plane. Individual $\beta$ strands that extend from these ligands form a $\beta$ sheet. The structural similarity of oxidized and reduced azurin, as well as the large self-exchange rate constant $\left[10^{5} \mathrm{M}^{-1} \mathrm{~s}^{-1}(17)\right]$, suggests relatively small reorganization barriers to electron transfer. A study of the temperature dependence of the redox potentials and ET rates in $\mathrm{Ru}(\mathrm{bpy})_{2}(\mathrm{im})$ (His83)-azurin is consistent with a reorganization energy of $0.8 \mathrm{eV}$, and it indicates that $\mathrm{Cu}^{+} \rightarrow \mathrm{Ru}^{3+}$ ET rates measured in $\mathrm{Ru}(\mathrm{bpy})_{2}(\mathrm{im})(\mathrm{HisX})$-azurins are close to $k_{\mathrm{ET}}^{\circ}(85)$.

We have measured the coupling along $\beta$ strands in Ru-modified derivatives of azurin (45). Five azurin mutants have been prepared with His residues at different sites on the strands extending from Met121 (His 122, His 124, His 126) and Cys 112 (His 109, His 107) (Figure 6); Ru(bpy) ${ }_{2}(\mathrm{im})^{2+}$ has been coordinated to these surface His groups and intraprotein $\mathrm{Cu}^{+} \rightarrow \mathrm{Ru}^{3+}$ ET rates have been 


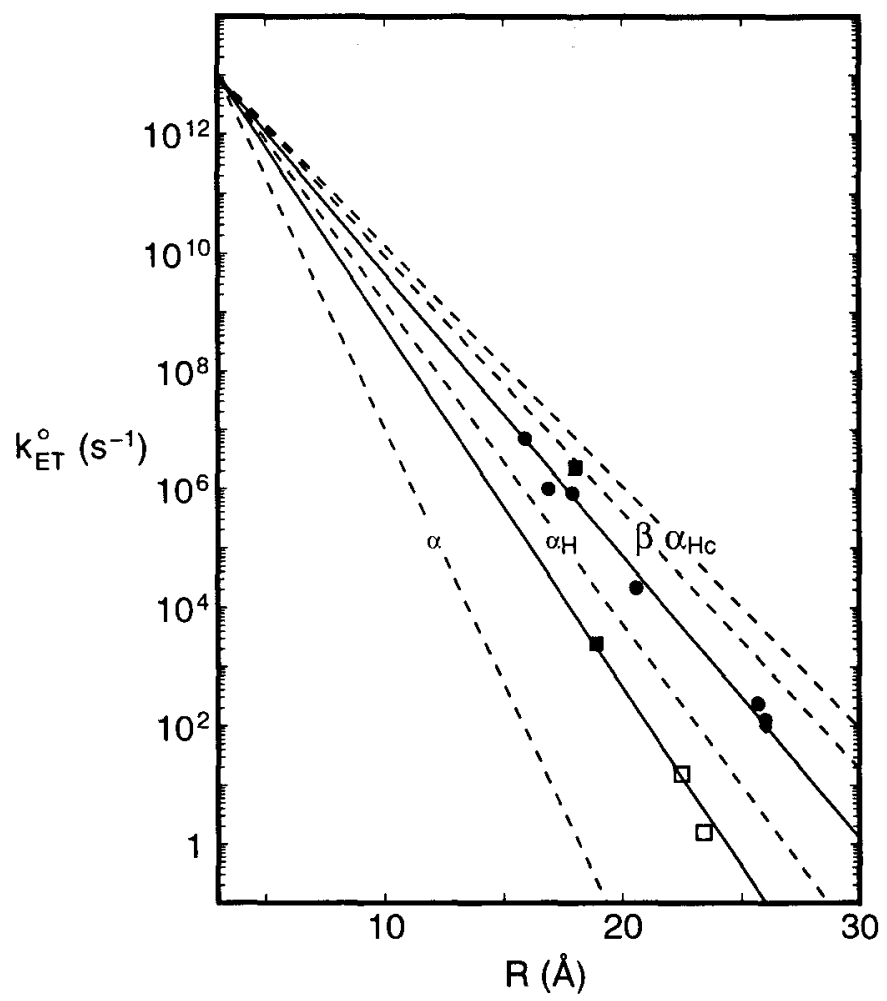

Figure 7 Plot of $\log \dot{k}_{\mathrm{ET}}^{\circ}$ vs $R$ : Ru-modified azurins (filled circles) $(45,85,98)$; Cys3-Cys $26\left(\mathrm{~S}_{2}\right)$ $\rightarrow \mathrm{Cu}^{2+} \mathrm{ET}$ in azurin (diamond) (103-105); $\mathrm{Ru}$-modified $\mathrm{Mb}$ (filled squares) $(106,107)$ and the $\mathrm{RC}$ (open squares) (86). Solid lines are the best linear fits with an intercept at $10^{13}$ and correspond to distance decays of $1.1 \AA^{-1}$ for azurin and $1.4 \AA^{-1}$ for $\mathrm{Mb}$ and the $\mathrm{RC}$.

measured using photochemical techniques $(45,98)$. The variation of $k_{\mathrm{ET}}^{\circ}$ with direct metal-metal separation $\left(R_{M}\right)$ is well described by an exponential function with a decay constant of $1.1 \AA^{-1}$ (Figure 7). The result is in remarkably good agreement with the slope predicted for the coupling decay along a strand of an ideal $\beta$ sheet.

Owing to the unusual $\mathrm{Cu}$ coordination, the couplings along different strands should show striking variations. Detailed electronic structure calculations indicate that the $\mathrm{S}$ atom of Cys112 has by far the strongest coupling to the $\mathrm{Cu}$ center; the His (imidazole) couplings are somewhat weaker than that of the Cys ligand, and the Met121 (S) and Gly45 (O) couplings are just a fraction of the Cys coupling $(99,100)$. These highly anisotropic ligand interactions strongly favor pathways that couple to the $\mathrm{Cu}$ through Cys112. Couplings 
along different $\beta$ strands would be expected to have the same distance-decay constants, but different intercepts at close contact. In light of these findings, the fact that the distance dependence of ET in Ru-modified azurin can be described by a single straight line (Figure 7) is quite surprising.

One explanation for uniform distance dependence of couplings along the Met121 and Cys1 12 strands is that strong interstrand hydrogen bonds serve to direct all of the distant couplings through the Cys112 ligand. A hydrogen bond between Met121(O) and Cys112(NH) could mediate coupling from the Ru complex bound to His 122. A second hydrogen bond [Gly123(O)-Phe110(NH)] would provide a coupling link for His 124 and His 126 ET reactions. The importance of the pathways that cross from the Met121 strand to the Cys112 strand depends upon the coupling efficiencies of the hydrogen bonds. Modelcomplex studies have demonstrated efficient electron transfer across hydrogen-bonded interfaces $(101,102)$. In the standard Beratan-Onuchic pathway model, hydrogen-bond couplings are distance-scaled and generally afford weaker couplings than covalent bonds (82). This procedure for calculating hydrogen-bond couplings cannot explain the similar distance dependences of ET along the Met121 and Cys112 strands in Ru-modified azurins. Treating the hydrogen bonds as covalent bonds in the tunneling-pathway model $\left(\varepsilon_{\mathbf{H}}=\right.$ $\varepsilon_{\mathrm{C}}^{2}$ ), however, does lead to better agreement with experiment (85).

Long-range ET from the Cys3-Cys26 disulfide radical anion to the copper in azurin has been studied extensively by Farver and Pecht (103-105). Estimates based on experimental rate data indicate that the $\mathrm{S}_{2} / \mathrm{Cu}$ coupling is unusually strong for a donor/acceptor pair separated by $26 \AA$. Relatively strong $\mathrm{Cu} / \mathrm{Ru}$ couplings also have been found for ET reactions involving $\mathrm{Ru}$-modified His83 (85). Interestingly, both the Cys3-Cys26 and His83 couplings fit on the $1.1 \AA^{-1}$ distance decay defined by the couplings along the Met 121 and Cys 112 strands (Figure 7). Strong interstrand hydrogen bonds may be responsible for the efficient couplings from the disulfide site and from His83. The tunnelingpathway model can only explain the electronic couplings to these two sites if hydrogen-bond couplings in this $\beta$-sheet protein are comparable to covalentbond couplings. Thus, $\beta$ sheets appear to be tightly knit structures that efficiently and isotropically mediate distant electronic couplings.

\section{$\alpha$-Helical Proteins}

Donor-acceptor pairs separated by $\alpha$ helices include the heme-Ru redox sites in two $\mathrm{Ru}$-modified myoglobins, $\mathrm{Ru}(\mathrm{bpy})_{2}(\mathrm{im})(\mathrm{HisX})-\mathrm{Mb}(\mathrm{X}=83,95$; Figure 8) (106-107) and the $\mathrm{Q}_{\mathrm{A}}-\mathrm{BCh}_{2}$ and $\mathrm{Q}_{\mathrm{B}}-\mathrm{BCh}_{2}\left(\mathrm{Q}_{\mathrm{A}}=\right.$ menaquinone, $\mathrm{Q}_{\mathrm{B}}=$ ubiquinone, $\mathrm{BCh}_{2}=$ bacteriochlorophyll special pair; Figure 9) redox centers in the photosynthetic reaction center $(1,86,108)$. The tunneling pathway from His 95 to the Mb-heme is comprised of a short section of $\alpha$ helix terminating 


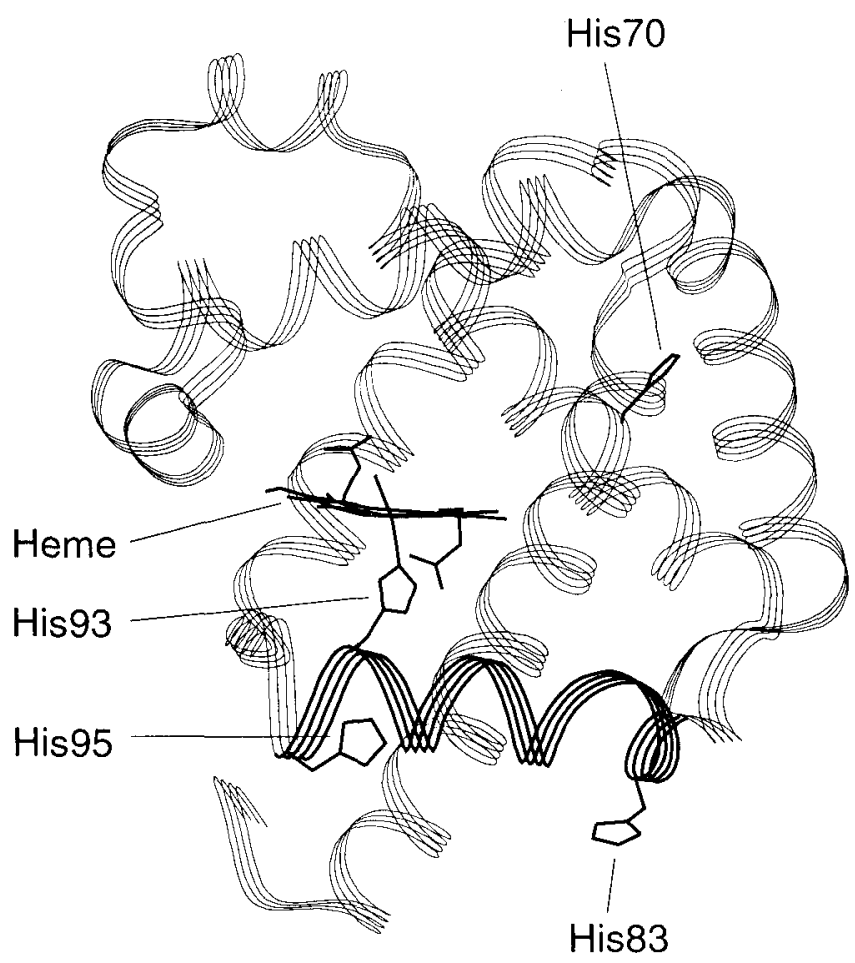

Figure 8 Structure of $\mathrm{Mb}$ including the His residues that have been coordinated to $\mathrm{Ru}(\mathrm{bpy})_{2}(\mathrm{im})^{2+}$.

at His93, the heme axial ligand. The coupling for the $\left[\mathrm{Fe}^{2+} \rightarrow \mathrm{Ru}^{3+}\right.$ (His95)]$\mathrm{Mb}$ ET reaction (106) is of the same magnitude as that found in $\mathrm{Ru}$-modified azurins with comparable D-A spacings. This result is consistent with the tunneling-pathway model, which predicts very little difference in the coupling efficiencies of $\alpha$ helices and $\beta$ sheets at small D-A separations (Figure 5). The electronic couplings estimated from the $\left[\mathrm{Fe}^{2+} \rightarrow \mathrm{Ru}^{3+}(\mathrm{His} 83)\right]-\mathrm{Mb}$ (107) and $\left[Q_{\bar{A}, \mathrm{~B}}^{-} \rightarrow \mathrm{BCh}_{2}^{+}\right]-\mathrm{RC}(86)$ ET rates, however, are substantially weaker than those found in $\beta$-sheet structures at similar separations, suggesting a larger distancedecay constant for $\alpha$ helices (Figure 7). Differences in hydrogen bonding in $\beta$ sheets and $\alpha$ helices may be responsible for this behavior. Infrared spectra in the amide $I\left(v_{\mathrm{CO}}, \mathrm{CO}\right.$ stretch) region show that hydrogen bonding in $\alpha$ helices $\left(v_{\mathrm{CO}}=1650-1660 \mathrm{~cm}^{-1}\right)$ is significant (nonhydrogen-bonded peptides, $\left.v_{\mathrm{CO}}=1680-1700 \mathrm{~cm}^{-1}\right)$, but it is not as strong as that in $\beta$ sheets $\left(v_{\mathrm{CO}} \sim 1630\right.$ $\left.\mathrm{cm}^{-1}\right)(109,110)$. If spectroscopically derived hydrogen-bond strengths reflect 


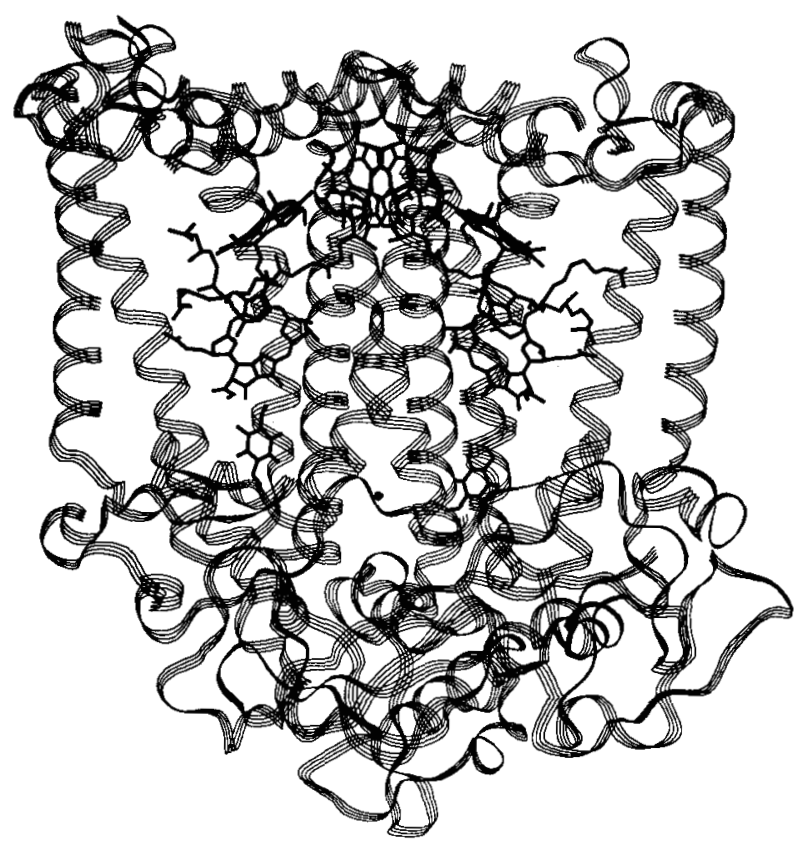

Figure 9 Structure of the photosynthetic reaction center from Rhodobacter sphaeroides (108).

electronic-coupling efficiencies, then long-range couplings at given distances along $\alpha$ helices will be weaker than those at corresponding distances along $\beta$ strands.

\section{Coupling Zones}

The tunneling-pathway model suggests that different protein secondary structures mediate electronic coupling with different efficiencies, a notion supported by experimental evidence. We can define different ET coupling zones in a rate vs distance plot (Figure 10). The $\beta$-sheet zone, representing efficient mediation of electronic coupling, is bound by coupling-decay constants of 0.9 and 1.15 $\AA^{-1}$. All of the ET rates measured with Ru-modified azurin fall in this zone. The $\alpha$-helix zone describes systems with coupling-decay constants between 1.25 and $1.6 \AA^{-1}$. ET rates from $\mathrm{Ru}$ (His83)-modified myoglobin and the two $\mathrm{RC} \mathrm{Q}-\mathrm{BCh}_{2}$ pairs lie in this zone. ET rate data are available for a $\mathrm{Ru}$-modified myoglobin (His70) where the intervening medium is not a simple section of $\alpha$ helix; the His70-Mb ET rate lies in the $\beta$-sheet zone (106). In the photosynthetic reaction center, two $\mathrm{BCh}_{2}^{\dagger}$ hole-filling reactions occur over relatively 


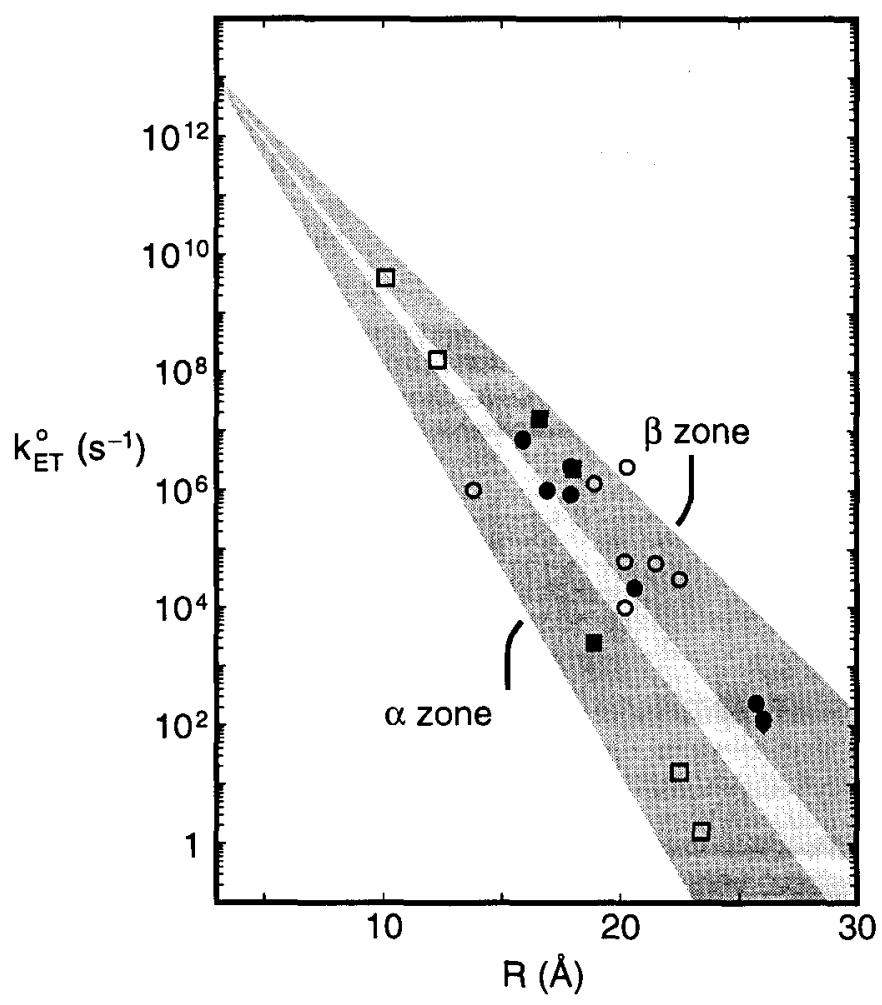

Figure 10 Plot of $\log k_{\mathrm{ET}}^{\circ} v s R$ illustrating the different ET coupling zones. Zones (shaded regions) Vare bounded by the following distance-decay lines: $\alpha$ zone, 1.25 and $1.6 \AA^{-1} ; \beta$ zone, 1.15 and 0.9 $\bar{z} \AA^{-1}$. The lighter shaded region is the interface between the $\alpha$ and $\beta$ zones. For Ru-bpy-modified - $p$ roteins, metal-metal separation distances are used. Distances between redox sites in the RC are 9 reported as edge-edge separations. Ru-modified azurin data (filled circles) $(45,85,98)$ : (Ru-label Site, $k_{\mathrm{ET}} s^{-1}, R \AA$ A ] His 122, 7.1 $\times 10^{6}, 15.9$; His 124, 2.2 $\times 10^{4}, 20.6$; His 126, $1.3 \times 10^{2}, 26.0$; His 109, $8.5 \times 10^{5}, 17.9$; His 107, 2.4 $\times 10^{2}, 25.7$; His83 1.0 $\times 10^{6}, 16.9$. Ru-modified myoglobin data (filled Usquares) (106, 107): His83 $2.5 \times 10^{3}, 18.9$; His $952.3 \times 10^{6}, 18.0$; His70 1.6 10, 16.6. Ru-modified >cyt $c$ data (open circles) (45): His39, $3.3 \times 10^{6}, 20.3$; His 33, $2.7 \times 10^{6}, 17.9$; His66, $1.3 \times 10^{6}, 18.9$; His72, $1.0 \times 10^{6}, 13.8$; His58, 6.3 × 10 $0^{4}, 20.2$; His62, 1.0 × 104, 20.2; His54, 3.1 $\times 10^{4}, 22.5$; His54(lle52), $5.8 \times 10^{4}, 21.5$. Cys3-Cys26(S2) $\rightarrow \mathrm{Cu}^{2+}$ ET in azurin (diamond) (103-105): $1.0 \times$ $10^{2}, 26$. RC data (open squares) (86): [donor to $\left.\mathrm{BCh}_{2}^{+}, k_{\mathrm{ET}}^{\circ} s^{-1}, R \AA\right] \mathrm{QA}_{\mathrm{A}}^{-}, 1.6 \times 10^{1}, 22.5 ; \mathrm{Q} \overline{\mathrm{B}}, 1.6$, $23.4 ; \mathrm{BPh}^{-}, 4.0 \times 10^{9}, 10.1$; cyt $c_{559}, 1.6 \times 10^{8}, 12.3$.

short distances where the differences between the $\beta$-sheet and $\alpha$-helix zones are less distinct: The observed rates lie between the two zones (86).

The coupling-zone concept sets the stage for analyses of ET rates in a wide variety of proteins. Cyt $c$ has a tightly packed structure but is not dominantly 


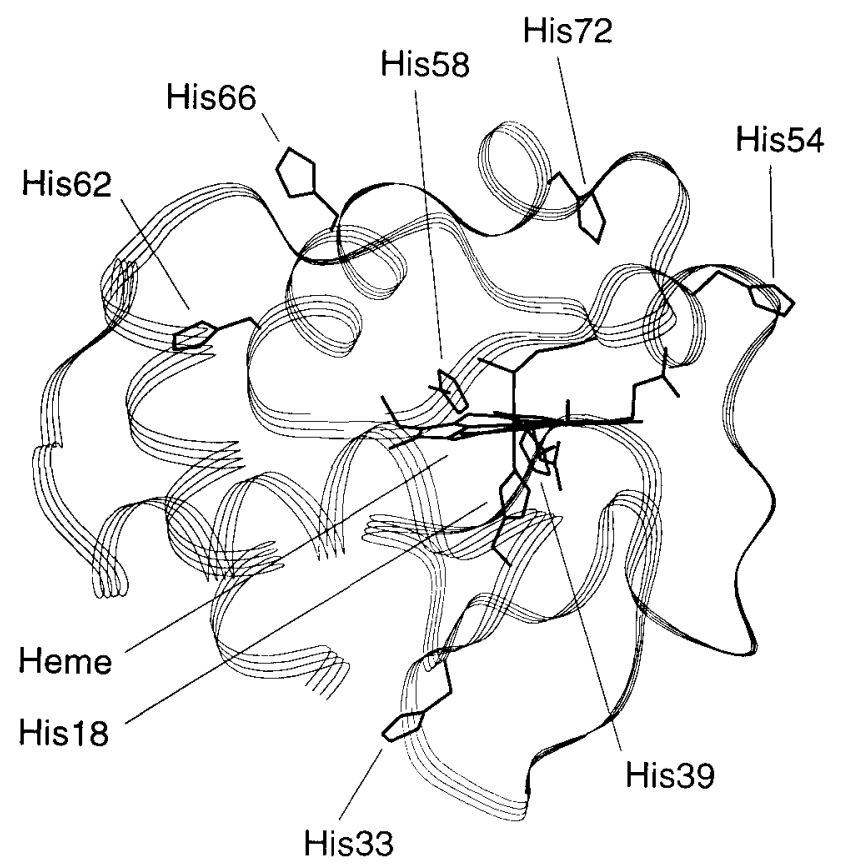

Figure 11 Structure of cytochrome $c$ including the His residues that have been coordinated to $\operatorname{Ru}(\text { bpy })_{2}(\mathrm{im})^{2+}$.

$\alpha$ helical or $\beta$ sheet (Figure 11). Analysis of the distance dependence of the $\mathrm{Fe}^{2+} \rightarrow \mathbf{R u}^{3+} \mathrm{ET}$ rates in eight $\mathrm{Ru}$-modified derivatives of cyt $c$ suggests that this protein mediates electronic coupling with an efficiency comparable to that found in azurin (45). Even though the structures separating redox sites are not simple $\beta$ strands or sheets, most of the tunneling pathways are fairly direct and therefore provide effective coupling routes. An exception is His72-modified cyt $c$ : The metal-metal separation distance in this protein is $13.8 \AA$, yet the ET rate is just $10^{6} \mathrm{~s}^{-1}$ (a value in the $\alpha$-helix zone; Figure 10). The poor coupling, however, is not due to an intervening $\alpha$ helix, but rather to a poor pathway that includes a through-space jump (42). The coupling estimated from a driving-force study of ET kinetics in Ru(bpy $)_{3}{ }^{2+}$-modified cyt $b_{5}$ places this system in the region between the $\alpha$-helix and $\beta$-sheet zones (53).

The variations in coupling efficiencies among different protein secondary structures could have important functional consequences. In a crude sense, $\beta$-sheet structures could act as conducting pathways through proteins while $\alpha$ helices might provide insulation against long-range electron transfer. In multisubunit redox enzymes such as cytochrome $c$ oxidase, the structure between 
subunits may play a key role in directing and regulating electron flow. Inspection of the structure of the oxidase reveals that ET from $\mathrm{Cu}_{\mathrm{A}}$ (subunit II) to cytochrome $a$ (subunit I) occurs over a $19-\AA \mathrm{Cu}-\mathrm{Fe}$ distance through a direct coupling pathway consisting of 14 covalent bonds and 2 hydrogen bonds $(9$, $10,111)$. Based on the relative bond couplings extracted from work on $\mathrm{Ru}$ modified proteins, the $19-\AA \mathrm{Cu}_{\mathrm{A}} /$ cyt $a$ ET rate falls in the efficient $(\beta)$ coupling zone of Figure 9 ( $k_{\mathrm{ET}}^{\circ}$ between $4 \times 10^{4}$ and $8 \times 10^{5} \mathrm{~s}^{-1}$ ). With these $k_{\mathrm{ET}}^{\circ}$ values, the reorganization energy for $\mathrm{Cu}_{\mathrm{A}}$ to cyt $a$ ET must be between 0.15 and 0.5 $\mathrm{eV}$ (111). It apparently is the combination of a low reorganization energy and an efficient ET pathway that allows electrons to flow rapidly with only a small change in free energy from the $\mathrm{Cu}_{\mathrm{A}}$ center of subunit II to cytochrome $a$ in subunit I of the oxidase.

\section{ACKNOWLEDGMENTS}

We thank BG Malmström, JN Onuchic, JJ Regan, MJ Therien, and K Warncke for helpful discussions. Our work on protein electron transfer is supported by the National Institutes of Health, the National Science Foundation, and the Arnold and Mabel Beckman Foundation.

Any Annual Review chapter, as well as any article cited in an Annual Review chapter, may be purchased from the Annual Reviews Preprints and Reprints service. 1-800-347-8007; 415-259-5017; email: arpr@ class.org

\section{Literature Cited}

1. Deisenhofer J, Epp O, Sinning I, Michel H. 1995. J. Mol. Biol. 246:429-57

2. Bixon M, Fajer J, Feher G, Freed JH, Gamliel D, et al. 1992. Isr. J. Chem. 32:369-518

3. Steffen MA, Lao KQ, Boxer SG. 1994. Science 264:810-16

4. Heller BA, Holten D, Kirmaier C. 1995. Science 269:940-45

5. Malmström BG. 1990. Chem. Rev. 90: 1247-60

6. Malmström BG. 1993. Acc. Chem. Res. 26:332-38

7. Gennis R, Ferguson-Miller S. 1995. Science 269:1063-64

8. Einarsdóttir Ó. 1995. Biochim. Biophys. Acta 1229:129-47

9. Tsukihara T, Aoyama H, Yamashita E, Tomizaki T, Yamaguchi H, et al. 1995. Science 269:1071-74

10. Iwata S, Ostermeier C, Ludwig B, Michel H. 1995. Nature 376:660-69

11. Winkler $J R$, Malmström BG, Gray HB. 1995. Biophys. Chem. 54:199-209

12. Varotsis $\mathrm{C}$, Zhang Y, Appelman EH,
Babcock GT. 1993. Proc. Natl. Acad. Sci. USA 90:237-41

13. Babcock GT, Wikström M. 1992. Nature 356:301-9

14. Rousseau DL, Han SH, Song SH, Ching YC. 1992. J. Raman Spectrosc. 23:55156

15. Kitagawa T, Mizutani Y. 1994. Coord. Chem. Rev. 135:685-735

16. Marcus RA. 1993. Angew. Chem. Int. Ed. Engl. 32:1111-21

17. Marcus RA, Sutin N. 1985. Biochim. Biophys. Acta 811:265-322

18. Winkler JR, Nocera DG, Yocom KM, Bordignon E, Gray HB. 1982. J. Am. Chem. Soc. 104:5798-800

19. Conrad DW, Zhang H, Stewart DE, Scott RA. 1992. J. Am. Chem. Soc. 114:9909-15

20. Yocom KM, Shelton JB, Shelton JR, Schroeder WE, Worosila G, et al. 1982. Proc. Natl. Acad. Sci. USA 79:7052-55

21. Matthews CR, Erickson PM, Van Vliet DL, Petersheim M. 1978. J. Am. Chem. Soc. 100:2260-62 
22. Nocera DG, Winkler JR, Yocom KM, Bordignon E, Gray HB. 1984. J. Am. Chem. Soc. 106:5145-50

23. Isied SS, Kuehn C, Worosila G. 1984. J. Am. Chem. Soc. 106:1722-26

24. Elias H, Chou MH, Winkler JR. 1988. J. Am. Chem. Soc. 110:429-34

25. Meade TJ, Gray HB, Winkler JR, 1989. J. Am. Chem. Soc. 111:4353-56

26. Therien MJ, Selman MA, Gray HB, Chang I-J, Winkler JR. 1990. J. Am. Chem. Soc. 112:2420-22

27. Crutchley RJ, Ellis WR Jr, Gray HB. 1985. J. Am. Chem. Soc. 107:5002-4

28. Axup AW, Albin M, Mayo SL, Crutchley RJ, Gray HB. 1988. J. Am. Chem. Soc. 110:435-39

29. Karas JL, Lieber CM, Gray HB. 1988. J. Am. Chem. Soc. 110:599-600

30. Winkler JR, Gray HB. 1992. Chem. Rev. 92:369-79

31. Fenwick C, Marmor S, Govindaraju K, English AM, Wishart JF, Sun J. 1994. J. Am. Chem. Soc. 116:3169-70

32. Jackman MP, Lim MC, Salmon GA, Sykes AG. 1988. J. Chem. Soc. Chem. Commun., pp. 179-80

33. Jackman MP, Lim MC, Sykes AG, Salmon GA. 1988. J. Chem. Soc. Dalton Trans., pp. 2843-50

34. Kostic NM, Margalit R, Che C-M, Gray HB. 1983. J. Am. Chem. Soc. 105:776567

35. Jackman MP, Sykes AG. 1987. J. Chem. Soc. Chem. Commun., pp. 65-66

36. Jackman MP, McGinnis J, Powls R, Salmon GA, Sykes AG. 1988. J. Am. Chem. Soc. 1 10:5880-87

37. Farver O, Pecht I. 1989. FEBS Lett. 244:379-82

38. Farver O, Pecht I. 1990. Inorg. Chem. 29:4855-58

39. Jacobs BA, Mauk MR, Funk WD, MacGillivray RTA, Mauk AG, Gray HB. 1991. J. Am. Chem. Soc. 113:4390-94

40. Osvath P, Salmon GA, Sykes AG. 1988. J. Am. Chem. Soc. 110:7114-18

41. Chang I-J, Gray HB, Winkler JR. 1991. J. Am. Chem. Soc. 113:7056-57

42. Wuttke DS, Bjernum MJ, Winkler JR, Gray HB. 1992. Science 256:1007-9

43. Casimiro DR, Richards JH, Winkler JR, Gray HB. 1993. J. Phys. Chem. 97: 13073-77

44. Mines GA, Bjerrum MJ, Hill MG, Casimiro DR, Chang I-J, et al. 1996. $J$. Am. Chem. Soc. 118:1961-65

45. Langen R, Chang I-J, Germanas JP, Richards JH, Winkler JR, Gray HB. 1995. Science 268:1733-35

46. Closs GL, Calcaterra LT, Green NJ, Penfield KW, Miller JR. 1986. J. Phys. Chem. 90:3673-83
47. Closs GL, Miller JR, 1988. Science 240: 440-47

48. Wasielewski MR, Niemczyk MP, Svec WA, Pewitt EB. 1985. J. Am. Chem. Soc. 107:1080-82

49. Fox LS, Kozik M, Winkler JR, Gray HB. 1990. Science 247:1069-71

50. Chen P, Duesing R, Graff DK, Meyer TJ. 1991. J. Phys. Chem. 95:5850-58

51. McLendon G, Miller JR. 1985. J. Am. Chem. Soc. 107:7811-16

52. McLendon G, Hake R. 1992. Chem. Rev. 92:481-90

53. Scott JR, Willie A, Mark M, Stayton PS, Sligar SG, et al. 1993. J. Am. Chem. Soc. 115:6820-24

54. Brunschwig BS, Ehrenson S, Sutin N. 1986. J. Phys. Chem. 90:3657-68

55. Brunschwig BS, Ehrenson S, Sutin N. 1987. J. Phys. Chem. 91:4714-23

56. Brunschwig BS, Sutin N. 1987. Comments Inorg. Chem. 6:209-35

57. Hoffman BM, Ratner MA. 1987. J. Am. Chem. Soc. 109:6237-43

58. Hoffman BM, Ratner MA, Wallin SA. 1990. In Electron Transfer in Biology and the Solid State: Inorganic Compounds with Unusual Properties, ed. M Johnson, pp. 125-46. Washington, DC: Am. Chem. Soc.

59. Brunschwig BS, Sutin N. 1989. J. Am. Chem. Soc. 111:7454-65

60. Brown GM, Sutin N. 1979. J. Am. Chem. Soc. 101:883-92

61. Williams RJP, Concar D. 1986. Nature 322:213-14

62. Bechtold $R$, Kuehn $C$, Lepre C, Isied SS. 1986. Nature 322:286-88

63. Moore GR, Williams RJP. 1980. Eur. J. Biochem. 103:523-32

64. Jeng M-F, Englander W, Elöve GA, Wand AJ, Roder H. 1990. Biochemistry 29:10433-36

65. Pascher T, Chesick JP, Winkler JR, Gray HB. 1996. Science 271:1558-60

66. Sun J, Wishart JF, Isied SS. 1995. Inorg. Chem. 34:3998-4000

67. Antonini E, Brunori M. 1971. Hemoglobin and Myoglobin in Their Reactions with Ligands. Amsterdam: NorthHolland

68. King BC, Hawkridge FM, Hoffman BM. 1992. J. Am. Chem. Soc. 114: 10603-8

69. Wang ZY, Pearlstein RM, Jia YW, Fleming GR, Norris JR. 1993. Chem. Phys. 176:421-25

70. Jia YW, Dimagno TJ, Chan CK, Wang ZY, Du M, et al. 1993. J. Phys. Chem. 97:13180-91

71. Pan LP, Hibdon S, Liu R-Q, Durham B, Millett F. 1993. Biochemistry 32: 8492-98 
72. Nilsson T. 1992. Proc. Natl. Acad. Sci. USA 89:6497-501

73. Newton MD. 1988. J. Phys. Chem. 92: 3049-56

74. Hopfield JJ. 1974. Proc. Natl. Acad. Sci. USA 71:3640-44

75. McConnell HM. 1961. J. Chem. Phys. 35:508-15

76. Liang C, Newton MD. 1992. J. Phys. Chem. 96:2855-66

77. Liang C, Newton MD. 1993. J. Phys. Chem. 97:3199-211

78. Curtiss LA, Naleway CA, Miller JR. 1993. Chem. Phys. 176:387-405

79. Shephard MJ, Paddon-Row MN, Jordan KD. 1993. Chem. Phys. 176:289-304

80. Beratan DN, Onuchic JN, Hopfield JJ. 1987. J. Chem. Phys. 86:4488-98

81. Onuchic JN, Beratan DN. 1990. J. Chem. Phys. 92:722-33

82. Onuchic JN, Beratan DN, Winkler JR, Gray HB. 1992. Annu. Rev. Biophys. Biomol. Struct. 21:349-77

83. Beratan DN, Betts JN, Onuchic JN. 1992. J. Phys. Chem. 96:2852-55

84. Beratan DN, Betts JN, Onuchic JN. 1991. Science 252:1285-88

85. Regan JJ, Di Bilio AJ, Langen R, Skov LK, Winkler JR, et al. 1995. Chem. Biol. 2:489-96

86. Moser CC, Keske JM, Warncke K, Farid RS, Dutton PL. 1992. Nature 355:796802

87. Farid RS, Moser CC, Dutton PL. 1993. Curr. Opin. Struct. Biol. 3:225-33

88. Skourtis SS, Regan JJ, Onuchic JN. 1994. J. Phys. Chem. 98:3379-88

89. Siddarth P, Marcus RA. 1990. J. Phys. Chem. 94:8430-34

90. Siddarth P, Marcus RA. 1990. J. Phys. Chem. 94:2985-89

91. Siddarth P, Marcus RA. 1992. J. Phys. Chem. 96:3213-17

92. Siddarth P, Marcus RA. 1993. J. Phys. Chem. 97:13078-82

93. Siddarth P, Marcus RA. 1993. J. Phys. Chem. 97:2400-5
94. Gruschus JM, Kuki A. 1992. Chem. Phys. Lett. 192:205-12

95. Gruschus JM, Kuki A. 1993. J. Phys. Chem. 97:5581-93

96. Friesner RA. 1994. Structure 2:339-43

97. Evenson JW, Karplus M. 1993. Science 262:1247-49

98. Langen R. 1995. Electron Transfer in Proteins: Theory and Experiment. PhD thesis. Calif. Inst. Technol., Pasadena. $208 \mathrm{pp}$.

99. Lowery MD, Solomon El. 1992. Inorg. Chim. Acta 200:233-43

100. Guckert JA, Lowery MD, Solomon EI. 1995. J. Am. Chem. Soc. 117:2817-44

101. Turro C, Chang CK, Leroi GE, Cukier RI, Nocera DG. 1992. J. Am. Chem. Soc. 114:4013-15

102. de Rege PJF, Williams SA, Therien MJ. 1995. Science 269:1409-1413

103. Farver O, Skov LK, Vandekamp M, Canters GW, Pecht I. 1992. Eur. J. Biochem. 210:399-403

104. Farver O, Pecht I. 1994. Biophys. Chem. 50:203-16

105. Farver O, Skov LK, Pascher T, Karlsson BG, Nordling M, et al. 1993. Biochemistry 32:7317-22

106. Langen R, Colón JL, Casimiro DR, Karpishin TB, Winkler JR, Gray HB. 1996. J. Biol. Inorg. Chem. In press

107. Casimiro DR. 1994. Electron Transfer in Ruthenium-Modified Recombinant Cytochromes and Myoglobins. PhD thesis. Calif. Inst. Technol., Pasadena. 263 pp.

108. Ermler U, Fritzsch G, Buchanon SK, Michel H. 1994. Structure 2:925-36

109. Schellman JA, Schellman C. 1962. In The Proteins, ed. H Neurath. New York: Academic. 2nd ed.

110. Susi H. 1972. Methods Enzymol. 26: 455-72

111. Ramirez BE, Malmström BG, Winkler JR, Gray HB. 1995. Proc. Natl. Acad. Sci. USA 92:11949-51 


\section{CONTENTS}

How to Get Paid for Having Fun, D E Koshland Jr 1

Relationships Between DNA Repair and Transcription, E C Friedberg 15

DNA Excision Repair, A Sancar 43

Selenocysteine, T C Stadtman 83

Mismatch Repair in Replication Fidelity, Genetic Recombination, and 101

Cancer Biology, $P$ Modrich and R Lahue

Mechanisms of Helicase-Catalyzed DNA Unwinding, $T$ M Lohman and K P Bjornson

Molecular Mechanisms of Drug Resistance in Mycobacterium

Tuberculosis, J S Blanchard

Protein Prenylation: Molecular Mechanisms and Functional

Consequences, F L Zhang and P J Casey

Protein Transport Across the Eukaryotic Endoplasmic Reticulum and

Bacterial Inner Membranes, T A Rapoport, B Jungnickel, and U Kutay

Molecular Biology of Mammalian Amino Acid Transporters, M S

Malandro and M S Kilberg

Telomere Length Regulation, C W Greider

The Structure and Function of Proteins Involved in Mammalian PremRNA Splicing, A Kramer

Molecular Genetics of Signal Transduction in Dictyostelium, C A Parent and $P$ N Devreotes

Structural Basis of Lectin-Carbohydrate Recognition, W I Weis and K Drickamer

Connexins, Connexons, and Intercellular Communication, $D$ A

Goodenough, J A Goliger, and D L Paul

Rhizobium Lipo-Chitooligosaccharide Nodulation Factors: Signaling Molecules Mediating Recognition and Morphogenesis, J Denarie, F Debelle, and J-C Prome

Electron Transfer in Proteins, $H$ B Gray and $J$ R Winkler

Crosstalk Between Nuclear and Mitochondrial Genomes, $R O P$ Poyton and $J$ E McEwen

Hematopoietic Receptor Complexes, J A Wells and A M de Vos

Interrelationships of the Pathways of mRNA Decay and Translation in Eukaryotic Cells, A Jacobson and S W Peltz

Recoding: Dynamic Reprogramming of Translation, $R$ F Gesteland and $J$ F Atkins

Biochemistry and Structural Biology of Transcription Factor IID (TFIID), $S$ K Burley and $R$ G Roeder 